\title{
Mella, Marcelo (2012). Elementos de ciencia POLITICA: CONCEPTOS, actORES Y PROCESOS. Vol. 1. Santiago: Facultad de Humanidades, USACH, RIL EDITORES.
}

\author{
Pablo A. Valenzuela (pavalenzuelag@u.uchile.cl)
}

UNIVERSIDAD DE CHILE

$\mathrm{E}$ $\mathrm{n}$ los inicios de los procesos recientes de democratización en América Latina, la democracia entre los ciudadanos albergaba una esperanza para construir un futuro en libertad y justicia. En las urnas se alojaban los sueños de los pueblos que habían luchado por acabar con los regímenes dictatoriales y con el terrorismo de Estado. El presidente argentino Raúl Alfonsín, baluarte de este horizonte de anhelos, señalaba que con la democracia se come, con la democracia se educa, con la democracia se cura, transmitiendo la idea de que el régimen democrático sería el advenimiento de la solución no sólo de los asuntos políticos de nuestra región, sino que también de los perennes problemas sociales que aquejan a nuestros países. La democracia, desde este punto de vista -y parafraseando a Guillermo O’Donnell- no es sólo un régimen de gobierno.

Pero esa esperanza se fue disipando con el paso de los años. La democracia acalló medianamente el tronar de los sables castrenses y ofreció a los ciudadanos la posibilidad de elegir a quienes gobernaban. Sin embargo, en muchos casos la democracia fue incapaz de garantizar la protección de los derechos individuales de los ciudadanos (Zakaria, 1997) o generar mecanismos de control por parte de los electores a la acción de los gobernantes (O’Donnell, 1994). Así, se consolidó en la región una democracia electoral que se debate entre el avance hacia formas más integrales y profundas de gobierno democrático (PNUD, 2004).

A partir de esa base, el trabajo de Marcelo Mella propone un extenso conjunto de temas para encauzar el análisis de las democracias latinoamericanas y mostrarle a la ciencia política caminos posibles que contribuyan al desarrollo de la disciplina desde un punto de vista socialmente relevante (pág. 17). En definitiva, se trata de generar estrategias, contenidos y aproximaciones que contribuyan a una mejor comprensión de los asuntos públicos y la práctica política para reducir la brecha entre la experiencia social y el saber disciplinario «canónico» (pág. 18). 
La obra se estructura en cuatro grandes secciones. La primera es sobre transformaciones culturales y políticas, en la que fundamentalmente el autor realiza una contextualización teórica del estado actual de la práctica política y social. Señala que la característica central que tiene la política contemporánea es la crisis, habida cuenta del malestar y el distanciamiento de los ciudadanos con las instituciones políticas y la democracia, en las dificultades para construir un sentido colectivo y normativo de la actividad política y en la permanencia de estructuras informales que complejizan el funcionamiento de las estructuras formales (pág. 30).

En este punto, vale señalar que el texto sugiere una crítica al institucionalismo por ser insuficiente para explicar los cambios de los procesos políticos y proponer una mirada demasiado lineal para el devenir democrático de nuestros países. No obstante, la crítica pierde fuerza cuando se sostiene frente a los desarrollos recientes del institucionalismo que han tendido a incorporar a su repertorio de análisis los mecanismos informales de organizar la sociedad, tanto desde un punto de vista económico (North, 1993), como político, con aplicaciones particulares al caso de América Latina (Helmke y Levitsky, 2006). En consecuencia, la crítica que desliza el autor resulta válida cuando se enfrenta al institucionalismo clásico e incluso al institucionalismo histórico visto desde el prisma más tradicional, pero se debilita significativamente al enfrentarla, por ejemplo, al institucionalismo de elección racional (Shepsle, 2006).

La segunda sección del trabajo es eminentemente conceptual, introduciendo una serie de debates teóricos en torno a algunas nociones centrales de la disciplina, como política, poder, democracia y Estado. Basándose en una revisión de la evolución histórica de los conceptos, el autor caracteriza las formas contemporáneas que cada uno de ellos ha adoptado. En ese sentido hace un uso profuso de la tipología que propone David Held en su trabajo Modelos de democracia (Held, 2001). Resulta interesante también en esta sección la forma en la que inserta al Estado contemporáneo en el contexto de la globalización reciente (pág. 90), aunque podríamos decir que adopta una mirada altamente estructural, que si bien no es tomada directamente del estructuralismo cepaliano -lo toma de un trabajo de Johan Galtung de 1995- el análisis obedece a los mismos conceptos de centro-periferia al que respondía el análisis estructuralista del sistema económico internacional de los años 60. Así también, se podría haber ganado mayor contundencia y profundidad en el análisis si el autor hubiese logrado un marco integrado de todos los conceptos.

La tercera sección está centrada en revisar algunos actores centrales del análisis politológico, como los partidos políticos, caracterizando la evolución histórica del con- 
cepto y su interacción con el Estado y la sociedad civil (pág. 99). Resulta interesante que el autor recoge algunas tipologías atingentes al proceso político latinoamericano, destacando los aportes que realizan Freidenberg y Levistky (2007) en torno al funcionamiento particular que tienen los partidos políticos en nuestra región, dado el alto nivel de informalidad con el que se manejan, lo cual haría fútil usar categorías propias de democracias avanzadas europeas para su caracterización.

A continuación incorpora un componente dinámico al análisis de los actores políticos mediante el uso de teoría de juegos, útiles para modelar el comportamiento de los actores bajo ciertas circunstancias e intentar construir la trayectoria de su actuación bajo la lógica del problema de la acción colectiva (págs. 160-162). En este punto, el análisis que realiza de partidos políticos y movimientos sociales resulta singularmente sofisticado cuando se compara con otros trabajos que se dedican a revisar la interacción de los actores dentro de un sistema político. Sin embargo, desde ese mismo punto de vista, la sección parece quedar incompleta al no incorporar algunos acápites dedicados al análisis de los grupos de presión y de interés, actores tradicionales de un sistema político y presentes en la mayoría de los cursos de introducción a la disciplina. Con todo, resulta también interesante incorporar a los medios de comunicación en este contexto, habida cuenta del rol creciente que juegan en el establecimiento de la agenda.

Finalmente, la sección cuatro se dedica a la revisión de los procesos políticos, consolidando así la mirada histórica que todo el trabajo busca desarrollar sobre los conceptos centrales de la ciencia política. De esta forma, se aboca a analizar los procesos de democratización y modernización tomando a autores clásicos del tema, como Rostow, Lipset y Hungtington. Adicionalmente incorpora a su análisis los procesos autoritarios y de transición a la democracia, llegando a los debates sobre gobernabilidad democrática, aunque dejando fuera las ideas más recientes que han surgido en torno al concepto de deepening democracy (Roberts, 1998; Wampler, 2012). También se extraña en esta sección -máxime la sofisticación histórica que busca plantear-, una revisión más detallada de los aspectos fundacionales de la democracia en los países latinoamericanos, como por ejemplo, las reformas constitucionales de 1918 en el Uruguay o la ley Sáenz Peña de 1912 en la Argentina (Smith, 2005).

En resumen, el autor buscar relevar nuevas formas de análisis que le permitan a la ciencia política transitar por nuevos caminos, denotando una aspiración normativa respecto a cómo debería ser la disciplina en la región. Sin embargo, los enfoques teóricos que el autor sugiere se podrían complementar con una propuesta metodo- 
lógica que permita operacionalizar el enfoque analítico del libro y así fortalecer su capacidad para realizar trabajo empírico en sintonía con la teoría.

Pero si nos mantenemos sólo en el espacio teórico - cayendo en un contrasentido evidente, pues el objetivo del libro es precisamente acercarse a la realidad social-podremos recorrer una serie de enfoques que sin ser del todo novedosos permiten incorporar un bagaje general por cada uno de ellos. Así mismo, no pareciera ser que el libro exprese alguna aspiración integradora de cada uno de los enfoques teóricos propuestos, y renuncie a la posibilidad de construir alguna propuesta teórica más sólida y abarcadora, quedándose así en un espacio introductorio y general de cada una de las miradas.

En conclusión, si tomamos al trabajo como un intento de recopilación de elementos útiles para el análisis de los procesos políticos latinoamericanos y la interacción entre los actores que le dan vida, el libro se transforma en una herramienta provechosa para alcanzar formas de análisis teóricas más profundas y sofisticadas. De esa forma, tiene un componente enciclopédico que puede ayudar a los estudiantes de ciencia política a acceder a los enfoques teóricos que propone.

El trabajo de Mella es ambicioso, en el sentido que en su intento por iluminar nuevos caminos para la ciencia política no alcanza a construir un derrotero claro para completar el objetivo que se propone. La revisión conceptual e histórica si bien resulta adecuada, en algunos puntos llega a ser superficial y no se divisa el hilo conductor que el autor busca introducir en las primeras páginas de su trabajo.

Elementos de ciencia política, como el primer tomo de una colección de tres volúmenes, resulta interesante a modo de manual introductorio a la disciplina y, probablemente, a los estudios políticos latinoamericanos. Puede ser provechoso para estudiantes que están empezando su carrera en la ciencia política y si esta es su finalidad principal, el libro está cerca de cumplir su objetivo; pero en la medida que busca sostener un mirada normativa y proponer un nuevo camino para el análisis politológico en nuestra región, ciertamente, se queda corto.

\section{Referencias Bibliográficas}

Freidenberg, F., y Levitsky, H. (2007). "Organización informal de los partidos políticos en América Latina”. Desarrollo Económico,Vol. 46, N 184, pp. 539-568.

Galtung, J. (1995). Investigaciones teóricas: sociedad y cultura contemporánea. Madrid:Tecnos.

Held, D. (2001). Modelos de democracia. Madrid: Alianza. 
Helmke, G., \& Levitsky, S. (2006). Informal institutions and democracy: Lessons from Latin America. Washington D.C:The Johns Hopkins University Press.

North, D. (1993). Instituciones, cambio institucional y desempeño económico. México: Fondo de Cultura Económica.

O’Donnell, G. (1994). “Delegative democracy”. Journal of democracy, Vol. 5, No 1, pp. 55-69.

PNUD (2004). La democracia en América Latina: Hacia una democracia de ciudadanas y ciudadanos. Buenos Aires: Alfaguara.

Roberts, K. (1998). Deepening Democracy?: The Modern Left and Social Movements in Chile and Peru. Standford, CA: Standford University Press.

Shepsle, K. (2006). “Rational choice institutionalism”. En, R. Rodhes, S. Binder, \& B. Rockman, The Oxford Handbook of Political Institutions. New York: Oxford University Press.

Smith, P. (2005). Democracy in Latin American: Political change in comparative perspective. New York: Oxford University Press.

Wampler, B. (2012). "Participation, Representation, and Social Justice: Using Participatory Governance to Transform Representative Democracy". Polity, Vol. 44, Nº, pp. 666-682.

Zakaria, F. (1997). The rise of illiberal democracy. Foreign Affairs, Vol. 76, Nº, pp. 22-42. 